\title{
Photo Filter Apps: Understanding Analogue Nostalgia in the New Media Ecology
}

\author{
ELENA CAODURO ${ }^{1}$, University of Southampton
}

\begin{abstract}
As digital media have become more pervasive and entrenched in our daily routines, a nostalgic countertrend has increasingly valued the physical and tactile nature of the analogue image. In the past few years, technologically obsolete devices, such as lo-fi cameras and vinyl records, have not faded out of sight completely but are instead experiencing a comeback. At the same time, digital media capitalise on the nostalgia for the analogue and fetishise the retro aesthetics of old technologies. This article explores the emergence of photo filter and effect applications which allow users to modify digital photos, adding signifiers of age such as washed-out colours, scratches and torn borders. It is argued that these new technologies, with programs such as Instagram, Hipstamatic and Camera 360, bring back the illusory physicality of picture-taking through digital skeuomorphism.
\end{abstract}

Drawing on media archaeology practice, this article interrogates the limits of the retro sensibility and the fetishisation of the past in the context of digital media, in particular by focusing on the case study of the start-up Instagram. This photo filter application neither merely stresses the twilight nature of photography nor represents the straightforward digital evolution of previous analogue features. Rather, it responds to the necessity to feel connected to the past by clear and valued signs of age, mimicking a perceived sense of loss. Faced with the persistent hipster culture and the newness of digital media, photo filter apps create comfortable memories, ageing pictures and adding personal value. As such, it will be argued that this phenomenon of nostalgia for analogue photography can be linked to the concepts of ritual and totem. By providing a critical history of Instagram as a photo-sharing social network, this article aims to explain new directions in the rapidly changing system of connective media.

\section{KEYWORDS}

Digital photography, social media, Instagram, vintage, nostalgia, totem.

\section{Introduction}

In 1888 George Eastman registered the Kodak name and launched a revolutionary device: roll film and the first pre-loaded camera, the Kodak No. 1, a successful but very expensive machine that cost \$25US, a large sum at that time (Richter 2006, 17). It was not until February 1900 with the commercialisation of the cheaper model, the Brownie Camera, made of wood and cardboard and sold instead at \$1US, that photography became a mass phenomenon. Since then, photography has become an established artistic medium, a business 
activity for professional photographers, and a global recreational hobby for dilettantes. Although Kodak ended camera and printer sales and filed for bankruptcy in 2012 (CEA 2013), millions of people around the globe still snap pictures with their analogue and digital devices. In July 2013, however, sales of digital cameras in the United States of America started to fall both in terms of revenue and in unit shipments, as more consumers turn to smartphones with high-resolution cameras to take snapshots and share them instantly through social media (CEA 2013, 1). ${ }^{2}$ We are again witnessing a transformation in the media ecology, where smartphones equipped with GPS, wireless connectivity and powerful cameras are used innovatively, changing digital photography and making their use easy and accessible at any time and at any place. The impact of the phenomenon is so widespread that Oxford English Dictionary recently declared 'selfie' as the most prominent term that significantly increased in use in the English language in 2013, becoming their International Word of the Year. Defined as 'a photograph that one has taken of oneself, typically one taken with a smartphone or webcam and uploaded to a social media website' (Oxford English Dictionary 2013), the buzzword 'selfie' epitomises the popularisation of photo-sharing websites and this new phase in digital photography. ${ }^{3}$

Photo filter applications such as Instagram, Snapseed and Hipstamatic mark a new era in digital photography, one which allows users to easily improve mediocre images taken with camera phones through the application of vintage filters, film scratches, and polarisation effects. This article provides a critical history of the rise of Instagram, situating it in relation to broader debates about mobile digital photography, the coexistence and overlapping of analogue and digital, and the emergence of social networks. By examining technical, economic, social and cultural aspects, I will clarify how recent transformations have driven our experience of photography and temporality. Focusing on a descriptive account of how photo filter apps affect our relationship with passing time, this article further explores the phenomenon of analogue nostalgia and why, in the digital age, even young generations, the so-called 'millennials', are driven back to the analogue, or its digital imitation. Secondly, such an integrated history of photo filter apps and social networks assists in the comprehension of the new media ecosystem and current tensions within digital tribes, namely how large groups of users interact within giant platforms.

\section{Instagram: technology and business model}

A particular trend in digital photography emerged around 2010: instead of sharing Photoshopped and airbrushed snaps, where flaws are hidden and imperfections minimised, amateur photographers - but also artists and professionals - began intentionally modifying their digital pictures with discolouration, technical faults and signs of ageing or other defects. This response to digital perfection has been primarily noticeable through smartphone and tablet applications, such as Instaplus, Picfx, Hipstamatic and Camera+, which allow users to swiftly retouch their own shots by playing with lighting, pre-set filters and frames to simulate the physicality of analogue photography. Photo filter and effect apps capitalise on the growing nostalgia for the analogue and fetishise the retro aesthetic by highlighting valued signs of age, such as torn borders, film scratches and yellowish colours, thus ultimately leading to an aestheticisation of imperfections (see Chandler and Livingston 2012). 
Instagram is probably the most popular of these applications. ${ }^{4}$ Created as a start-up by Kevin Synstrom and Mike Krieger and launched in October 2010, it reported 200 million monthly active users in March 2014 (Tam 2014). Throughout Autumn 2013, Instagram experienced a spectacular growth: a $23 \%$ increase, more than other well-established social platforms like LinkedIn, Google+ and Twitter (Bennett 2014). It is available for free for a variety of operating systems; initially it was only available for Apple's iPhone, iPad and iPod Touch, but it later produced versions for Google Android phones and an official beta for Windows. Instagram can be defined as a user-generated content site with a strong networking component that enables users to take pictures and short videos, and share them on different platforms, including Tumblr and, if location tracking is enabled, Foursquare. ${ }^{5}$

On its website, visitors are welcomed with the page shown below (figure 1); the words in bold, Instagram's marketing pitch, underline the strength of its social appeal: instantaneity, attractiveness and entertainment. In an instant one-click procedure, users can modify their photos through a series of pre-set filters that reproduce specific colour casts associated with different decades, as well as recreating the look of iconic cameras such as the Polaroid, with its characteristic square white border. In an interview in The Telegraph, one of the company's founders, Kevin Systrom is quoted explaining the concept behind the origin of Instagram:

The idea was to make mobile photography fast, beautiful and fun. We learned from experience that taking photos on the phone didn't lead to the results that we wanted, so we created the filters and tools to achieve a more artistic experience. $[\ldots]$ That being said, we also wanted to share those photos with friends and we felt that existing social networks were optimized around other mediums. So we went out and created a new social network focused on photos of what you are doing. (Richmond 2011)

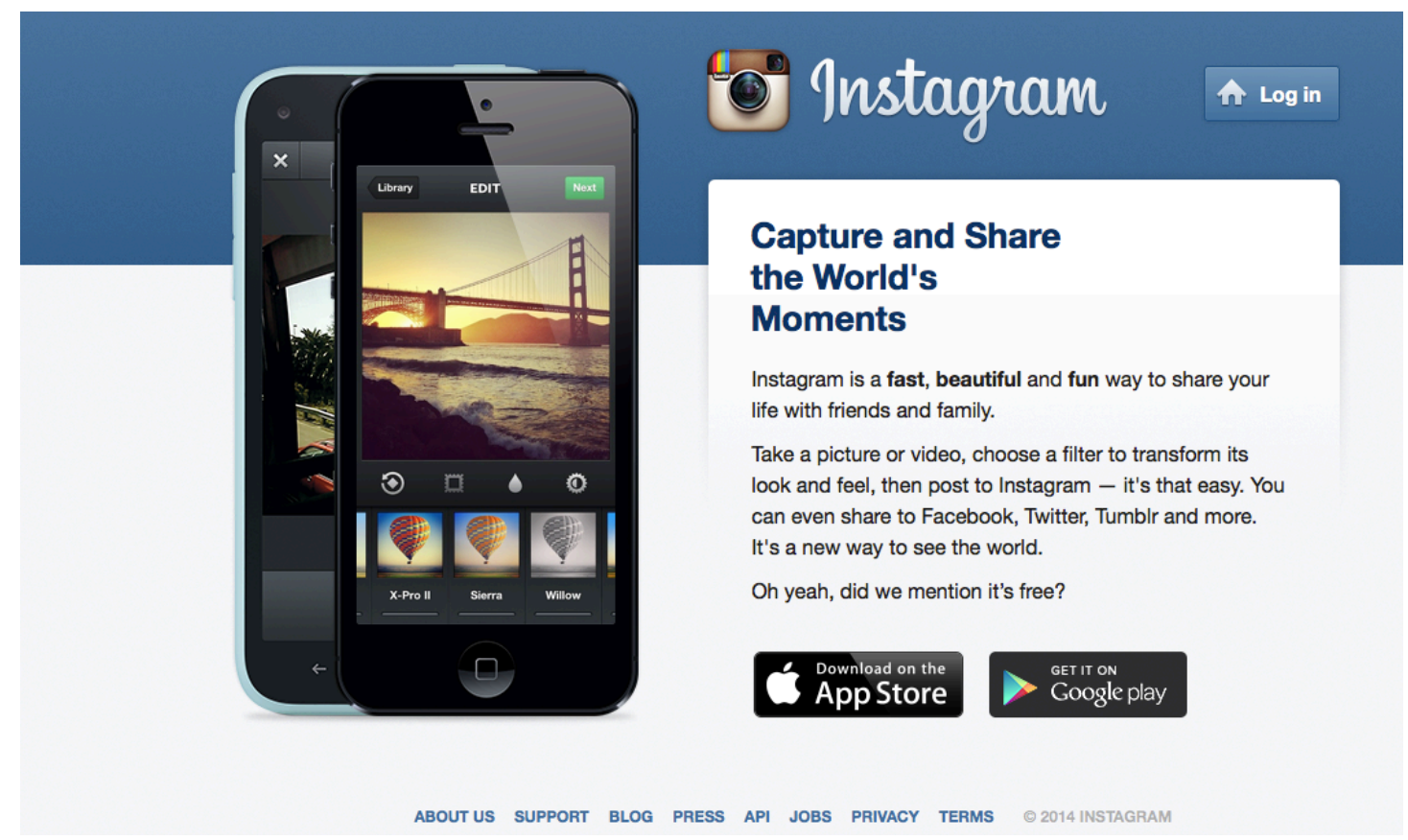

Figure 1: http://instagram.com 
Robert Willim points out that central to the concept of Instagram was chiefly the possibility of being included 'in a larger web of image sociality', where pictures can be uploaded, shared and commented on $(2013,354)$. The social network component of Instagram's identity is crucial to its existence, as well as the ample lists of pre-set filters and effects. In truth, Instagram started out in a time when large social networking services such as Facebook, Twitter and YouTube had already built their brands and online identities. Its interface, therefore, had to reflect this and offer the similar functions of posting, commenting, favouring and distributing. By adopting a language that bridges the neologisms introduced by networking giants Facebook and Twitter, Instagram was able to rival similar applications: the heart symbol denotes the Facebook 'Like', while tagging images through the hashtag symbol '\#' is directly borrowed from Twitter trending features.

Given that the new media ecosystem is in constant flux, and many social networking sites grow in popularity as swiftly as others lose favour with online communities, critical debates in this field must respond quickly and flexibly. There is no established or defined method in place to measure the success or failure of applications such as Instagram, considering that what users define as an accomplishment might clash with the ultimate scopes of creators or owners and vice versa. Commercial forces can put some pressures and declare the spectacular success of some applications, but also their decline; in particular, the decision on how to monetise a start-up and generate new income becomes a crucial moment in the lives of these free apps. Overall, however, one can see Instagram as an example of 'a successful microsystem', what José van Dijck defines as a 'platform that survived the ecosystem vagaries' $(2013,90)$. It rose above direct competitors by adapting to its social environment, offering stable and reliable software with great connectivity. Amid a number of contenders, it even won the race against one of the first photo-sharing platforms, Flickr, founded in 2004 and now part of the Yahoo group. ${ }^{7}$ When Facebook bought Instagram for approximately $\$ 1$ billion in cash and stock in April 2012 (Rusli 2012), the photo filter app emerged reinforced, growing more than the mother company over the past few months (Bennett 2014). This acquisition reveals the ambiguity of what success represents in the context of the relationship between users, creators and investors.

In fact, the changes to Instagram's business model adopted since Facebook's involvement have ignited anxious responses from users, and it remains to be seen whether Instagram will survive further changes. In December 2012, when Instagram announced changes to its Terms of Service which granted the company the rights to sell users' images without notification or compensation, many members migrated to similar if smaller platforms (Perlroth and Wortham 2012). More recently, Instagram declared that it would begin generating money through advertisements, and although the first Instagram ad drew significant complaints from users, the profile of the first advertiser, Michael Kohr, actually gained a huge amount of followers on the social network (Taube 2014). Instagram thus hopes to start monetising the popular photo-sharing network with creative and selected ads from leading brands. In addition, Instagram also introduced the feature Instagram Direct, which allows users to send pictures to specific people. This goes against the initial modus operandi of the application; Instagram focused immediately on public usage, a mix of amateurs and professionals catering to a vast and heterogeneous pool of enthusiasts. With images published as public items, Instagram did not develop as a site for users interested in community building and intimate sharing. These changes can be connected to the operation of acquisition run by Facebook, although its founder, Mark Zuckerberg, has often sustained the independence of the photo 
filter app. As I go on to explain in the course of this article when addressing the ritual of photo-sharing, this episode signals a transformation in the social practice of photography and should be contextualised within natural processes in the social media ecology, where with the swift growth of start-ups comes the incorporation by existing large platforms. Van Dijck explores this phenomenon, arguing that:

\begin{abstract}
Companies often appeared less interested in communities of users than in their data - a by-product of making connections and staying connected online.

Connectivity quickly evolved into a valuable resource as engineers found ways to code information into algorithms that helped brand a particular form of online sociality and make profitable in online markets - serving a global market of social networking and user-generated content. Large and influential platforms such as Facebook, Twitter, YouTube, and LinkedIn exploded in terms of users and monetizing potential, alongside countless smaller profit and non-profit sites. As a result of the interconnection of platforms, a new infrastructure emerged: an ecosystem of connective media with a few large and many small players. The transformation from networked communication to 'platformed' sociality, and from a participatory culture to a culture of connectivity, took place in a relatively short time span of ten years. $(2013,4)$
\end{abstract}

The popularity of Instagram should therefore be understood within two frameworks: the culture of connectivity and convergence (see van Dijck 2013 and Jenkins 2006) and the widespread hype for all things vintage or retro. The notorious photo filter app is embedded in an ecosystem where large platforms have become crucial in driving new forms of sociality (van Dijck 2013,23), but also where new and old media coexist and collaborate. In the light of this, Instagram ought to be situated within what Henry Jenkins, Sam Ford and Joshua Green define as 'spreadable media' (2013), and more specifically within a complex structure where the circulation of media texts is negotiated between marketing strategies and grassroots tactics. $^{8}$ In addition to such 'spreadability', Instagram rides the wave of vintage and retro hype, where anything from the recent past, or faux old items, suddenly becomes fashionable, and hence valuable and desirable. The following section discusses the complexities of the current retro hipster movement, ${ }^{9}$ and more specifically the peculiarities of nostalgia for analogue image production that are facilitated by Instagram.

\title{
Timeless nostalgia: riding the wave of retro hype
}

Simon Raynolds claims that "instead of being the threshold to the future, the first ten years of the twenty-first century turned out to be the "Re" Decade. The 2000 s were dominated by the "re-" prefix: revivals, reissues, remakes, re-enactments. Endless retrospection' (2011, xi). This trend for regurgitating the past - particularly the visuality of the past - has continued in the second decade of the new millennium. The nostalgia for analogue imaging is negotiated by two different but concurrent phenomena emerging from the relationship between analogue and digital media, namely the self-conscious fetish for cultural objects from the immediate past, and the imitation of the style, design and sound of analogue technologies.

First of all, we have the recuperation and fascination for old media objects. For many of us, digital technologies have become more pervasive and part of our daily routines, but the 
market for technologically old devices, such as typewriters and vinyl records, is alive and well. While we increasingly listen to music as MP3 files, watch films and TV series via streaming channels or through downloading, and communicate with friends via internetbased applications and social networks, old analogue technologies are experiencing a resurgence of interest. In the US and UK, for instance, LPs represent a small portion of overall music album sales. This growing niche continues to expand; 2012 was the fifth consecutive year in which vinyl experienced record-breaking sales thanks to collectors and the audiophiles' appreciation for a better sound (Nielsen SoundScan and Nielsen BDS 2013). Filmmakers go back to old formats, aspect ratios of previous decades and shoot with vintage videocameras, like Pablo Larraín who used a 1983 U-Matic for his feature film No (2012), in order to recount Pinochet's loss of power in 1980s Chile with more authenticity. As far as photography is concerned, analogue cameras did not fade out of sight completely; the analogue camera community Lomographic Society International, in short Lomography, became a testament to the resurgence of analogue photography and particularly lo-fi and toy cameras. Founded in 1992 by a group of Austrian students, Lomography is both an art movement and a commercial enterprise, which sells analogue cameras (the Lomo LC-A camera produced by the Russian LOMO PLC) and various accessories, and promotes the distinctive and unique aesthetic qualities of analogue imaging though gallery exhibitions and magazines. ${ }^{10}$

Alongside the demand to revive older media, which have experienced a diminishing or cessation of production, nostalgia for the look and texture of analogue imaging has emerged in the appropriation of analogue design and aesthetics by digital media. Digital skeuomorphism is a form of complex intertwining between analogue and digital, where, for instance, the user-friendly interfaces of many computer programs emulate the sounds and shapes of objects in the real world because of their familiarity. This is particularly evident in calendar software present on our digital screens, which, in fact, imitates the appearance of paper desk calendars; similarly, in painting software, the cursor becomes a brush.

Furthermore, it is common that when taking a picture with a mobile phone or a digital camera, the device imitates the sound of a mechanical shutter. In their seminal study Remediation:

Understanding New Media, Jay David Bolter and Richard Grusin (1999) counter the modernist myth of the new, arguing that digital technologies actually pay homage, refashion and reinvent earlier media. Underlying the false dichotomy between indexical and digital, old and new technologies in cinema, Philip Rosen proposes the term 'digital mimicry' (2001, 304 ) to discuss the ability of digital media to imitate analogue forms. He maintains that 'digital imaging is not separable from prior histories of mediated representation on screen surfaces, but overlaps with them. Any argument that treats digital imagery as radically novel must deal with such overlaps' (ibid., 314). Instagram, which allows users to create visually nostalgic pictures through filters, is a primary example of digital mimicry, and it lends support to Rosen's argument against considering analogue and digital as opposite terms.

The aesthetics of Instagram filters consists of a combination of choices: film textures, frames, tones, and additional elements including film scratches and dust specks. Particular framing formats can be replicated: rounded corners, film perforations and burnt edge effects can be easily reproduced in a click. One of the favourite add-ons is the 'Polaroid frame', with its iconic white setting. But replicas are not limited to the famous instant camera, as some are suggestive of styles from different times and place. These include imitating the look from earlier analogue cameras such the Russian LOMO or the Holga from Hong Kong. Filters for 
sepia tones, black-and-white, and washed out colours function as signifiers of time and age, whereas others reproduce the typical errors and casual effects that often occurred in the analogue era with inexperienced photographers, including overdeveloped film, light leaks and unintended halation. Notably, while such errors were typically caused by cheap material, inexpensive plastic lenses, light leakage, and unskilled film processing, they have actually become popular additions to the lo-fi look (Smith 2011), perhaps because mobile digital photographers hark back to the spontaneity of the chance image taken on a limited roll of film.

The reasons why so many social network users have turned to photo filter apps to modify their digital pictures are multiple, as are the roots of the heterogeneous phenomenon of analogue nostalgia, which include both the purchase of vintage products (clothes, design objects, old vinyl records) and retro imitations. In his article 'The Faux Vintage Photo', Nathan Jurgenson (2011) notes that an easy answer could be that the low quality of phone cameras has led users to take 'stale photographs which are then made more interesting when given a faux-vintage filter'. In truth, many current models of smartphone offer very high quality cameras, and professional photographers know that even gritty pictures can sometimes be better than a technically perfect shot. Nevertheless, I would suggest that a technological explanation only partially indicates why we modify digital pictures into looking specifically retro. Using Instagram filters relates in part to the desire to mask amateurish pictures. This, however, does not fully explain the rise in popularity among artists and professionals, and it does not necessarily entail that average users lazily engage with pictures. From a consumer marketing perspective, the rise of photo filter apps is the result of 'repro nova' marketing strategies: promotional techniques that combine old styling with high technologies (Brown 2001, 7). ${ }^{11}$ In other words, Instagram emerges from a culture where the old, the authentic, the analogue is still a repository of value and appreciation. It also represents a depository of memories and timeless nostalgia, but this nostalgia is not merely 'yearning for yesterday' (Davis 1979, 16), but is a creative tool for the present. Given that young users of social networks have never experienced the time when light leaks and underdevelopment were common problems in analogue photography, the nostalgia for these signifiers of time does not necessarily induce emotional responses linked to the manual handling of photographic film. Rather, instagrammed photos ironically play with temporality by adding visual signs of decay.

Nostalgia is generally assumed as 'a positive preference for the past involving negative feelings toward the present and future' (Davis 1979, 18), implying therefore an idealisation of the past and a refusal of the present. But the current interest in technologically obsolete devices and photo filter apps is not a mere attempt to mourn superseded technologies (and, more broadly, the past), but is rather an attempt to reclaim physicality. The application of filters and effects aims to render photos more important and real, given that the physicality of the analogue still grants a significance that digital has not yet achieved (Jurgenson 2011). Both analogue and digital photography conjure the past, but instagrammed photos graphically age our captured moments to show the here and now as a past for which we are already nostalgic. This simulated physicality of instagrammed photos represents a way to stay connected with the past, generate comfortable memories, and display authentic slices of the immediate past. Jurgenson is therefore correct when he states that faux-vintage photos create 'nostalgia for the present', by 'placing the present into the context of the past and authenticity' (2011). The past is still associated with strong emotions, and the physicality of analogue 
imaging, with its smell, shape and tactility, becomes something for which we yearn. Therefore, by invoking properties of the physical, even though these are very often exaggerated, instagrammed pictures recall a past thanks to digital interventions.

However, what I want to argue is that the phenomenon of analogue nostalgia is not necessarily anti-modern and as Pam Cook $(2004,4)$ observes in Screening the Past: Memory and Nostalgia in Cinema, 'nostalgia can form part of a transition to progress and modernity'. Supporting this claim, Svetlana Boym argues that nostalgia is not always retrospective and distinguishes two tendencies of nostalgia, the restorative and the reflective:

Restorative nostalgia stresses nostos (the return home) and attempts a transhistorical reconstruction of the lost home. Reflective nostalgia thrives in algia, the longing itself, and delays the homecoming. Restorative nostalgia protects the absolute truth, while reflective nostalgia calls it into doubt. (2001, xviii)

One interesting way of interpreting the rise of photo filter apps is to think of them as a form of 'reflective nostalgia', defined by Boym as taking a 'sensual delight in the texture of time' $(2001,49)$. Retro filters, dust speck and halation effects do not aim to recreate the past exactly as it was; their adoption is an intentional act to challenge temporality and ironically play with it. Instagrammed photos recuperate the physicality of analogue imaging, signalling a perceived loss of authenticity in digital pictures. ${ }^{12}$ By faking the emotion of old photographs through the one-click application of vintage texture, instagrammed photos are indeed signifiers of a timeless nostalgia, but in a playful and ironic manner. Users create new possibilities in the present by sampling through templates of the past in order to give a personal attribute to slices of their own lives. The phenomenon of photo filter apps is also due to the desire to imprint distinctiveness to ordinary and average shots. Thus, it should be clear that instagrammed photos display a simulated nostalgia for a past, as they are themselves in line with Jean Baudrillard's (1983) description of simulation. They are indeed not really aged through the passing of time, but, instead, by a mobile application. As such, Instagram's effects generate what Lisa Chandler and Debra Livingston call 'a simulacrum of analogue authenticity', and 'function as signifiers of one's awareness of what has cultural currency' $(2012,4)$. The popularity of photo filter apps ought to be understood through different notions, namely the desire to adjust, improve and personalise ordinary and bland digital snaps, the fruit of marketing campaigns praising the style of the past, and the wish to retain the physicality and authenticity of analogue imaging.

\section{Beyond authenticity: Instagram and its critics}

It is beyond the scope of this article to discuss the indexical authenticity of both analogue and digital photography, but it is sufficient to summarise here the findings of several scholars (Biro 2013; Buse 2010a), who agree on the greater authenticity of analogue photos. In his comparative study of Bernt and Hilla Becher's analogue photographs and Andreas Gursky's digital images, Matthew Biro $(2013,354)$ defends the authenticity of the analogue due to its tangible and physical nature, and for being a product of a direct optical process. In other words, the ability of digital photography to authentically represent reality is weaker because 
of the digital manipulation (ibid., 353). Similarly, Peter Buse (2010a) supports this argument when analysing the transition between Polaroid and digital imaging. Buse (ibid., 226) maintains that Polaroid photos are indexically authentic because they are unique and cannot be reproduced but, most importantly, they are attached to their material supports. Generally speaking, critics of digital photography feared a loss of depth, history, feeling and texture, features that seem innate in analogue imaging and 'missing in the cold inhuman perfection of the digital' (Murray 2013, 179). However, new media theorists, such as Lev Manovich, debunk the myth of a pure digital image, explaining that digital pictures can be reproduced endlessly, but at a great loss of quality. There is, in fact, much more degradation between copies of digital shots than between copies of analogue photos (Manovich 1995). Criticism towards Instagram, Hipstamatic and other photo filter apps reproduce similar accusations and denigratory claims to those applied to the early digital images when compared to analogue photos. This reveals not only an irritation against hipster and retro culture, but also against continuity between analogue photography and digital imaging. Notably, when new technologies are introduced, and foremost when they become popular, sentiments of mistrust, corruption and falsification emerge to defend the status quo, or better to champion a radical rupture with the analogue.

Photo filter apps were explicitly designed with effects that could transform and mediate reality. Some of the criticism against Instagram, for instance, is based on the argument that imitations of lo-fi cameras and the faux-vintage look actually distort and ruin the authenticity and visual representation (Bevan 2012). Filters for colour corrections, contrast enhancement, polarisation or various effects might distort the image, but we should not forget that this distortion is intentional and the very purpose of the altering practice (Krapp 2011). It is useful to reiterate the creative potential of digitally flawed photos. Fabricated signs of imperfection, which are so typical of Instagram's aesthetics, are related to creative appreciations of inefficiencies and errors in digital culture. Photo filter apps ought to be understood within the complex phenomena of glitch, noise and computational flaws in digital technologies which, according to Peter Krapp (2011), hold great creative potentiality. The signs that imitate human and technical faults become, in the context of digital photography, a vital and essential resource for creativity, as they add distinctiveness and feeling to pristine photos.

The digital signs of time and memory that characterise photo filter apps can be employed separately or in combination. Despite the routine introduction of new filters, there are, of course, limits to the forms of analogue nostalgia that Instagram can provide. Users are able to work with different combinations, multiple pre-set filters and effects to create new looks, but as Chandler and Livingston argue, photo filter apps are paradoxically both 'creatively enabling and constraining' $(2012,12)$. Not only is there a limit to the number of filters but also the squared film aspect ratio - another element reminiscent of the analogic Polaroid format - poses some challenges for the amateur photographer. In fact, pictures contain fewer subjects, and users are pushed to take close-up shots and to rigorously select what they want to immortalise within the small squared frame, thus refining their critical and artistic sense. In this way, Instagram is creatively enabling because it elevates the routine, the quotidian, allowing us to play with light and filters, looking for value even in banal shots. Chandler and Livingston further maintain that 'these apps are creative tools, and thus the final outcomes are affected by the photographer's creative thinking and the meanings they wish to convey' (ibid.). At the same time, however, the constraints are such that we are already observing a plethora of sunsets, home-made meals and hype cycles modified with similar filters; popular 
amateur photography, therefore, brings about a certain visual sameness, facilitated by the availability of digital tools to adjust the look of personal snaps. To sum up, mobile technologies such as Instagram encourage and strengthen well-established practices. On the one hand they offer new possibilities: they might enhance the abilities of the casual user, assisting in the creative transformation of simple shots into more sophisticated images, but they are also numbing or blocking some capacities. The creation of faux-vintage photographs with these pre-set filters is limited by the software itself and specifically by its finite combinations. Thus, one could foresee a situation with no prospects of development; unless the subject in focus is particularly original or fascinating, there might be 'a risk of reaching a creative dead end' with careless applications of the same 'retro ' 77 ' filters (ibid.). There are, of course, exceptions that reinforce the idea of creative possibility despite the banality of certain pictures and the limitation of filters. In December 2013 Thomas Jullien published An Instagram Short Film on Vimeo, a travelogue video that puts together 852 instagrammed photos from different users in a narrative and cohesive way. ${ }^{13}$ The filmmaker exploits the sameness of hundreds of photos of famous monuments, tube trains and 'selfies' to generate a new creative product in stop motion. In this context, the creative use of Instagram's filters to transform pictures can be positioned between skilfulness and dilettantism.

\section{Changing ritualistic practices?}

The study of photo filter apps should move beyond issues of authenticity, indexicality and representation, and be better contextualised within social media. Jullien's video would have not been possible without the new possibilities offered by digital photography, namely the ease in modifying and reproducing photos and the convergence between mobile telephony and internet, which largely contribute to the practice of photo-sharing. It is important to realise that changes in the practice of digital photography, and in the transition from analogue imaging to the digital, do not constitute a complete revolution; there is much continuity, and changes are built on small ritualistic adjustments.

Since the mid-1990s, photography has evolved exponentially and, with the introduction of digital cameras and photo-software, taking impressive pictures has become straightforward even for the relatively inexperienced. Digital cameras integrated with mobile phones and smartphones enhance the phenomenon, allowing people to take pictures anywhere and at any time. Mundane and banal moments are captured to keep a souvenir of the present instant and build an archive of experiences. As such, mobile digital photography preserves the quality of immediacy held by point-and-shoot cameras, compact and easy-to-use devices, which were primarily employed for taking pictures of family events, parties and holidays. With the rise of camera phones, smartphones and tablets, point-and-shoot cameras have been overshadowed given that many now tend to share pictures of their everyday lives online. Nonetheless, online photo sharing is not an entirely novel social practice, as it builds on private rituals, old routines of distribution and sharing in private environments, such as the exchange of family pictures in the intimate home setting, but also in shared public spaces, when collections were exchanged in galleries and artists' studios (van Dijck 2013, 94). Nowadays, digital photos work to foster connectedness amongst online friends and followers and to contribute to the construction of a personal online identity. 
Group identity has been a ubiquitous feature of human existence throughout history: belonging to a similar 'tribe' of individuals is deeply rooted in us, as we tend to stick with large groups that retain similar distinctiveness. Here I adapt anthropological notions, specifically those of tribe, clan and totem, in a manner similar to Steve Wheeler's (2009) attempts to map virtual learning communities, in order to further elaborate on the attractiveness of photo filter apps. As a result of the explosion of the social network phenomenon, there are many virtual clans within the internet tribe. Anthropologists differentiate between tribes (totally separate communities) and clans (subgroups that are part of a larger tribe). Social networking sites generate a series of digital clans as a consequence of a sustained interaction through chatting, commenting and photo sharing. In his study of learning technologies, Wheeler describes the emergence of digital subgroups, arguing that:

Each clan $[. .$.$] has a totem, a symbol that represents it and distinguishes it from$ other, possibly rival clans. In primitive clans, the totem was often a representation of an animal or tree. Durkheim suggests it is easier for clan members to project their feelings of awe toward a totem than toward something as complex as the clan itself. For virtual clans, their totems the traditional rallying points for all tribal activity - are patently the social networking tools within the World Wide Web. Not only are these digital spaces objects of intense interest and rallying points for the clans, they also act as transmitters of units of cultural knowledge. $(2009,67)$

Similarly, sociologists like Massimo Canevacci are focusing their attention on technology, applying structuralist methods to the understanding of online communities. According to Canevacci (quoted in Meckien 2013), scientific progress has symbolically reversed the power of nature over culture and 'new totemism puts technology as the defining character of humanity'. As far as photo sharing is concerned, Instagram attracts at the level of the group and plays the totemic, symbolic role of social bonding. As a virtual clan, Instagram finds its distinctiveness in the application of filters and effects to snapshots, and its members, the Instagrammers, generally trade in affirmative comments, liking attractive images, commenting on friends' achievements, and sharing pictures on other platforms. Social networks, including Instagram, are redefining personal identities through adjustments and updates, which function to signal our cultural identity and clan membership. As such, Instagram's memes, cyclical elements shared between communities, perpetuate a shared culture.

\section{Conclusions}

In addressing the changes of photographic practices in the early twenty-first century, one must acknowledge that the renewed popularity of toy film cameras - the LOMO LC-A first and foremost, but also others - is intrinsically related to the phenomenon of photo filter apps such as Instagram and Hipstamatic. The two trends are highly connected and show not only opposing and similar facets of analogue nostalgia, but also how analogue and digital practices coexist and speak to each other. While simple analogue cameras, such as Hong Kong's Dianas and Holgas, produce an authentic vintage look, Instagrammed pictures present a simulation, and imitation of old visual aesthetics. In the course of this article I have analysed Instagram from a technological and marketing perspective, arguing that its popularity is due 
to profiting from the connective culture of social media and the retro and vintage hype circle. Instagram has made the visual style of pre-set filters and digital effects, characterised by saturated colours or pale washed out palettes, the prevailing imagery among millions of users in social media.

Countering criticism for a loss of professionalism and authenticity, I maintain that pre-set filters and digital effects are not essentially good or bad; in fact, the practice of transforming digital photos with mobile applications can be both creatively liberating and constraining in exploring new imaginative trajectories. Given the limits imposed by transformative combinations, it seems that, when so extensively used, filters appear more the fruit of a trend rather than a deliberate creative selection. Photo filter apps tend to render everyone's digital photos the same. While the trend started as an attempt to make pictures and memories look personal and unique through the application of filters and signs of imperfection, it might now suffer from unimaginativeness and sameness. Exceptions do exist and confirm the positive artistic attributes - it is sufficient to think about Thomas Jullien's effort to piece together overlooked instagrammed pictures of feet, tube trains and Paris and New York monuments for a short artistic film - but the novelty will soon begin to fade away. The phenomenon of Instagram and similar mobile applications may wane in the near future, but, given its creative possibilities, one can always expect future variations, spin-offs, and merging of practices.

The reasons for the popularity of the vintage look are multiple. On the one hand, it responds to the perceived lack of 'physicality' and 'materiality' in the digital photography universe. To paraphrase Buse's $(2010,228)$ interpretation of Polaroid's digital reproductions,

Instagrammed snapshots compensate for the fact that they are not tactile and tangible through digital skeuomorphic effects. On the other hand, the one-click post processing becomes an acceptable aspect of sharing pictures taken with smartphones in order to mask amateurish shots or poor quality pictures and creatively personalises instant moments. Although iPhones and other new generation smartphones have good photo quality compared to point-and-shoot cameras, yet optimum lighting is a rare occurrence when you want to take a picture. Instead of fighting the tide of digital perfection, Instagram's users embrace the weakness and strength of mobile digital photography. Instagrammed photos are defined by a set of visual signs which represent a distinctive retro aesthetic and a visual identifier of a specific virtual clan. Photo filter apps may be a passing fashion, yet in their analogue nostalgia they effectively define a virtual clan and their culture.

\footnotetext{
${ }^{1}$ I would like to express my gratitude to Paula Blair for her constructive suggestions during the preparation of this article.

${ }^{2}$ The smartphone market is renowned for its unpredictability: in 2010 Nokia and RIM were the top vendors sharing 50\% of the total, while in 2012 they accounted for only 10\%, whilst Samsung and Apple shared the majority. Although smartphones constitute only the minority of handsets sold globally, estimate calculate that there are 'only' over 1 billion of smartphones currently in use worldwide (mobiThinking 2013).

${ }^{3}$ Adding to the context that has given rise to the smartphone photography as a ubiquitous activity, large platforms, such as Google+ and Facebook have activated their own instantaneous photo uploading features.

${ }^{4}$ The fortune of Instagram has been contagious: its filtering aesthetics were applied to other established services. In 2012 the photo editor, Snapseed, which features a number of filters, was acquired by Google, and later the same year, Twitter included a number of photo filters in its interface, notably including names such as 'vintage'
} 
and 'gritty' (Willim 2012, 354). In the course of this article I will be using the adjective 'Instagrammed' to broadly define all digital images modified with photo filter and effect applications.

${ }^{5}$ Since March 2014 the now Facebook-owned Instagram has been taking distance from its current location provider Foursquare. It is currently testing the feature Facebook Places with a selected group of users (van Grove 2014).

${ }^{6}$ It is worth remarking that while the heart symbol is unmistakable, to 'like' something on Facebook has evolved and it is often used now to acknowledge a post or comment. Connectivity has brought about the merge of practices typical of specific social networks; not only 'hashtags' are enabled on Instagram, but for some months on Facebook, too.

${ }^{7}$ Flickr went through many changes through its existence; some of them - the requirement to sign up with a Yahoo ID_-generated strong responses from its members. For further analysis of the model adopted by Flickr, see van Dijck (2011) and Murray (2013).

${ }^{8}$ See also Jenkins' earlier formulation of 'convergence culture' (2006: 2), which defines the changed power relations between media companies and active users/consumers.

${ }^{9}$ Definitions of the term 'hipster' are approximate, but here I generally refer to contemporary youth subcultures associated with alternative music and film taste and with a retro sensibility.

${ }^{10}$ Even though it was considered an obsolete technology, Polaroid, the famous instant camera, has been readopted by younger generations. Petitions to save the production and organisations, such as The Impossible Project, currently sustain the constant demand for these products (cf. Buse 2010a and 2010b).

${ }^{11}$ Stephen Brown $(2001,7)$ uses as an example of 'repro nova' the New Beetle Volkswagen, which imitates the iconic first model but is an adapted version for the twenty-first century. Within the field of brand strategy, Brown further differentiates two more forms of retro marketing: 'repro', when an old product is reintroduced as it was and 'repro de luxe', when an already nostalgic product is launched. For a study on consumer behaviour, marketing and photography consumption see Morlot 2013.

${ }^{12}$ Digital photographs are erroneously associated with immateriality: their physicality is intangible and invisible, but it is constituted by a series of binary codes stored in hard drives or memory cards (van Dijck 2007, 109).

${ }^{13}$ An Instagram Short Film can be viewed at http://www.iamthomasjullien.com/albums/an-instagram-short$\underline{\text { film/. }}$ Accessed 20 June 2014.

\section{References}

Baudrillard, J. (1983) Simulacra and Simulation, Ann Arbor, MI: University of Michigan Press

Bennett, S. (2014) 'Twitter Grew Just $2 \%$ in the last 6 months (Instagram $+23 \%$, Facebook -3\%) [STATS]', AllTwitter: The Unofficial Twitter Resource, [online], 23 January. Accessible at http://www.mediabistro.com/alltwitter/social-media-usergrowth-2013_b54402. Accessed 25 January 2014.

Bevan, K. (2012) 'Instagram is Debasing Real Photography', TheGuardian.com, 19 July. Accessible at http://www.theguardian.com/technology/2012/jul/19/instagramdebasing-real-photography. Accessed 15 December 2013.

Biro, M. (2013) 'From Analogue to Digital Photography: Bernd and Hilla Becher and Andreas Gursky', History of Photography, 36(3), 353-66

Bolter, J. D. and Grusin, R. (1999) Remediation: Understanding New Media, Cambridge, MA: The MIT Press 
Boym, S. (2001) The Future of Nostalgia, New York: Basic Books

Brown, S. (2001) Marketing: The Retro Revolution, London: SAGE

Buse, P. (2010a) 'Polaroid After Digital: Technology, Cultural Form, and the Social Practices of Snapshot Photography', Continuum: Journal of Media and Cultural Studies, 24(2), 215-30

--- (2010b) 'The Polaroid Image as Photo-object', Journal of Visual Culture, 9(2), 189-207

CEA [Consumer Electronic Association] (2013) Digital America 2013: State of the U.S. Consumer Electronics Industry, [online]. Accessible at http://content.ce.org/PDF/2013DigitalAmerica_abridged.pdf. Accessed 20 January 2014.

Chandler, L. and Livingston, D. (2012) 'Reframing the Authentic: Photography, Mobile Technologies and the Visual Language of Imperfection', $6^{\text {th }}$ Global Conference Visual Literacies Exploring Critical Issues, Oxford, UK, 3-5 July. Accessible at http://www.inter-disciplinary.net/at-the-interface/wpcontent/uploads/2012/05/chandlervlpaper.pdf. Accessed 15 December 2013.

Cook, P. (2004) Screening the Past: Memory and Nostalgia in Cinema, London and New York: Routledge

Davis, F. (1979) Yearning for Yesterday, New York: Free Press

Jenkins, H. (2006) Convergence Culture: Where Old and New Media Collide, New York and London: New York University

Jenkins, H. Ford, S., and Green, J. (2013) Spreadable Media: Creating Value and Meaning in a Networked Culture, New York and London: New York University Press

Jurgenson, N. (2011) 'The Faux-Vintage Photo', Cyborgology, [blog], 14 May. Accessible at http://thesocietypages.org/cyborgology/2011/05/14/the-faux-vintagephoto-full-essay-parts-i-ii-and-iii/. Accessed 25 January 2014.

Krapp, P. (2011) Noise Channels: Glitch and Error in Digital Culture, Minneapolis, MN: University of Minnesota Press 
Manovich, L. (1995) 'The Paradoxes of Digital Photography', in Photography After Photography, [online exhibition catalogue], Germany. Accessible at http://manovich.net/TEXT/digital_photo.html. Accessed 25 January 2014.

Meckien, R. (2013) 'Sociologist and Anthropologist Look at Technology as a New Totemism', Institute of Advanced Studies of the University of Sao Paulo News, [online], 17 October. Accessible at http://www.iea.usp.br/en/news/sociologist-andanthropologist-look-at-technology-as-a-new-totemism. Accessed 25 January 2014.

mobiThinking (2013) Global Mobile Statistics 2013 Part A: Mobile Subscribers; Handset Market Share; Mobile Operators, [online]. Accessible at http://mobithinking.com/mobile-marketing-tools/latest-mobilestats/a\#mobilephonepenetration. Accessed 20 January 2014.

Morlot, E. (2013) Nostalgic Consumption Behaviours Among Young Generations in Photography: A Comparative Approach of Instagram and Analogue Photography. MA Dissertation, Umeå University. Accessible at http://urn.kb.se/resolve?urn=urn:nbn:se:umu:diva-76235. Accessed 1 May 2014.

Murray, S. (2013) 'New Media and Vernacular Photography', in M. Lister (ed.), The Photographic Image in Digital Culture, London and New York: Routledge, pp. 165-82

Nielsen SoundScan and Nielsen BDS (2013) The Nielsen Company \& Billboard's 2012 Music Industry Report, [online]. Accessible at http://www.scribd.com/doc/118975417/THE-NIELSEN-COMPANYBILLBOARD\%E2\%80\%99S-2012-MUSIC-INDUSTRY-REPORT. Accessed 20 January 2014.

Oxford English Dictionary (2013) 'Selfie', The Oxford English Dictionary Online. Accessible at http://www.oxforddictionaries.com/definition/english/selfie. Accessed 20 January 2014.

Perlroth, N. and Wortham, J. (2012) 'Instagram's Loss Is a Gain for Its Rivals', The NYTimes.com, 20 December. Accessible at http://bits.blogs.nytimes.com/2012/12/20/instagrams-loss-is-other-apps-gain/. Accessed 20 January 2014.

Raynolds, S. (2011) Retromania: Pop Culture's Addiction to Its Own Past, London: Faber and Faber

Richter, J. (2006) Inventing the Camera, New York: Crabtree Publishing Company 
Richmond, S. (2011) 'Instagram, Hipstamatic and the Mobile Photography Movement', Telegraph.co.uk, 19 August. Accessible at http://www.telegraph.co.uk/technology/news/8710979/Instagram-Hipstamatic-andthe-mobile-photography-movement.html. Accessed 20 January 2014.

Rosen, P. (2001) Change Mummified: Cinema, Historicity, Theory, Minneapolis, MN: University of Minnesota Press

Smith, K. (2011) 'Digital Lo-fi Photography', Digital Photography Review, 12 December. Accessible at http://www.dpreview.com/articles/9771282693/digital-lo-fiphotography-part-1. Accessed 20 January 2014.

Tam, D. (2014) 'Instagram Passes 200M Active Users', CNet.com, 26 March. Accessible at http://www.cnet.com/uk/news/instagram-passes-200m-active-users/. Accessed 1 May 2014.

Taube, A. (2013) 'Michael Kors' Widely Hated Instagram Ad was Actually a Massive Success', BusinessInsider.com, 6 November. Accessible at http://www.businessinsider.com/michael-kors-wins-with-first-instagram-ad-2013-11. Accessed 1 May 2014.

van Dijck, J. (2007) Mediated Memories in the Digital Age, Stanford, CA: Stanford University Press

--- (2011) 'Flickr and the Culture of Connectivity: Sharing Views, Experiences, Memories', Memory Studies, 13(2), 401-15

--- (2013) The Culture of Connectivity: A Critical History of Social Media, Oxford and New York: Oxford University Press

van Grove, J. (2014) 'Instagram Test Locates you Without Foursquare', CNet.com, 25 March. Accessible at http://www.cnet.com/uk/news/instagram-removingfoursquare-in-places-test/. Accessed 1 May 2014.

Weeler, S. (2009) 'Digital Tribes, Virtual Clans', in S. Weeler (ed.), Connected Minds, Emerging Cultures: Cybercultures in Online Learning, Charlotte, NC: IAP, pp. 65-75

Willim, R. (2013) 'From the Claude Glass to Instagram', in CSDS Sarai Collective (eds), Projections: Sarai Reader 09, Delhi: Impress, pp. 352-59 